INTERNATIONAL JOURNAL OF MULTIDisciplinARY RESEARCH AND ANALYSis

ISSN(print): 2643-9840, ISSN(online): 2643-9875

Volume 04 Issue 12 December 2021

DOI: 10.47191/ijmra/v4-i12-21, Impact Factor: 6.072

Page No.- 1917-1922

\title{
Registrar Information System through SMS
}

\section{April Rose Articuna Zaragosa}

Institute of Information and Computer Studies Northern Iloilo Polytechnic State College, Estancia, Iloilo

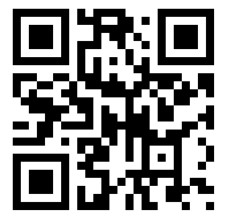

ABSTRACT: The Registrar Information System through SMS is design and develop a computer-based system that is able to provide a real-time information through SMS to students regarding of their academic records. It has a two-way interactive text messaging functionality in a Registrar's office of Northern Iloilo Polytechnic State College Main Campus, Estancia, lloilo. The architectural design used in this system is two-tier architecture. The developed system employed a descriptive and developmental research design. Respondents of the study were the 354 students enrolled officially in School Year 2016-2017 using a standard questionnaire International Standard Organization / International Electrotechnical Commission 25010. The Rapid Application Development Model was used in the Software Development Life Cycle. MySQL for the database, vb.net language and Windows operating system development environment. The usability of the feature of the developed system is Very Good in terms of delivering important academic information to every student. The performance of the developed system is fully functional when it comes to all the processes such as enrolling, encoding the grades, reliable and efficient to the students in sending/ receiving academic information provided to clienteles.

KEYWORDS: Registrar information, SMS, Students academic record, Rapid Application Development Model

\section{INTRODUCTION}

Today, Short Message Service (SMS) is the most widely-used data application in the world. SMS has become more than just a way to text it also lets us receive, updates, keep track of our records and much more [1]. The SMS-based system makes life easier for people every day. They help to perform tasks quicker and communication with friends and family with the press on the button. It plays a significant role in the school system as well.

In 2003, an SMS-Based Event Notification System was developed [2]. The issues fought that those gateways that support scheduling don't mostly allow users to cancel scheduled on SMS message. So they arrived to propose a system that they can use SMS to transact any transaction. This study has successfully designed and developed an enterprise class mass SMS mailing system that support multiple users as well as multiple SMS gateways, providing a unified interface and common set of features across many SMS gateways which prevent vendor lock-in as users can choose among multiple SMS vendor gateways. Another major feature provided by the new system is the introduction of SMS message scheduling. This feature makes SMS message scheduling possible across all SMS gateways including those that do not internally support scheduling. Moreover, users can also cancel any scheduled message if the need be.

Keeping and handling personal information and academic performance of students in the school are very important. It is one of essential tasks of the registrars' office of any school. Registrars are custodians of students' records. They register students, record grades, prepare student transcripts, evaluate academic records, plan and implement commencement, oversee the preparation of college catalogs and schedules of classes, and analyse enrollment and demographic statistics." In short, any and all administrative work is done through the office of the registrar [3]. In the developed UC-Main Registrar's Office Student Document Management and Monitoring System [4]. This study focuses on monitoring and management of the student documents. They're issues is on how they are going to have a will lessen their time in finding and obtaining the student's record. Instead of manual processing, they just have to search the student's identification number using their system and it will be locate eventually the student's document and monitor the lacking of student's report. Currently, the office of registrar makes the transactions easy and fast manner.

In 2003, the proposed Malaysia Yemen Student Information System (YSIS) with SMS (Short Messaging System) Notification [5] is to take an important role of developing integrated information about Yemen's students that study at all Malaysia's university. YSIS 


\section{Registrar Information System through SMS}

will develop in order to overcome the problems with the current manual system. The system management will give a benefit to every student, cultural attached to integrate, transfer, and get updated data and information faster and easier. However, it used mobile technology to develop part of SMS notification. The system is available as long as internet connectivity is available. The system can now be accessed without limitation of the time and place. Their initial design decisions of the new system already recognized and identified.

As a state-owned higher education institution, Northern Iloilo Polytechnic State College (NIPSC) is mandated to provide higher vocational, professional, and technical instruction and training in the fields of industry, agriculture, fishery, engineering and sciences, and short-term vocational technical continuing courses. NIPSC has to adapt the challenges brought about by the advancement of technology as to the various business processes to ensure the efficient delivery of services to its clients.

This study focuses on the transformation of the current manual system used by the NIPSC in giving the information to the students thru its Short Message Service version. The system defines the process of recording, preparing, evaluating, planning, implementing, scheduling and analysing academic records information about the students. It provides students better service from the registrar's office when it comes to the information's of their academic records.

The main purpose of this study is to design and develop a computer-based system that is able to provide real-time information through SMS to students regarding of their records. Determine the level of the usability of the developed features of the Registrar Information System through SMS. Evaluate the performance of the developed Registrar Information System Through SMS in terms of reliability, and efficiency of the information provided to clienteles.

\section{METHODOLOGY}

\subsection{System Development Life Cycle}

Software Development Life Cycle (SDLC) is a series of phases that provide a common understanding of the software building process. SDLC includes a detailed plan for how to develop, alter, maintain, and replace a software system. The software development model used in this study was the Rapid application development (RAD) model that is based on prototyping and iterative development with no specific planning involved. The process of writing the software itself involves the planning required for developing the product [6].

The RAD divides the process into four distinct phases they are requirements planning phase, user design phase, construction phase and the cutover phase that uses minimal planning in favor of rapid prototyping. A prototype is a working model that is functionally equivalent to a component of the product. In RAD model the functional modules are developed in parallel as prototypes and are integrated to make the complete product for faster product delivery. Figure 1 shows the RAD model.

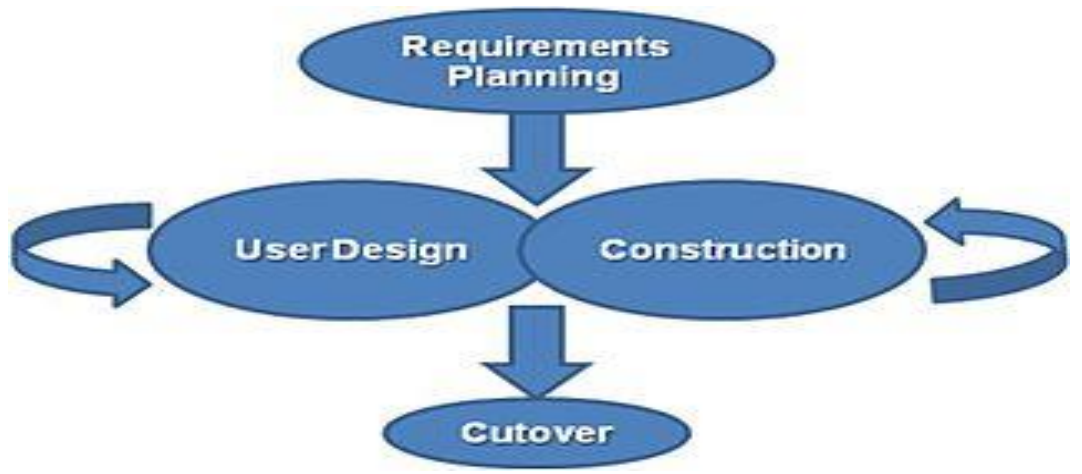

Figure 1. The Rapid Application Development Model

\subsection{Logical Architecture Model}

The architectural design is one important document that shows the hardware, software and networks environments of the system. The developed system used to run in Two-tier architecture. Two-tier architecture is a software architecture in which a presentation layer or interface runs on a client, and a data layer or data structure gets stored on a server[7]. The application logic is divided into two parts, one on the server and the other is on the client. They cooperate to accomplish the desired tasks. Clientserver architecture, the architecture of a computer network in which many clients (remote processors) receive service from a centralized server (host computer). Client computers provided an interface to allow a computer user to request services of the server and to display the results the server returns. Servers wait for requests to arrive from clients and responded to them. 


\section{Registrar Information System through SMS}

Ideally, a server provides a standardized transparent interface to clients so that clients need not be aware of the specifics of the system that is providing the service. The researcher designs a two-tier architecture, in which the server takes the responsibility of data storage, data access and part of the application logic. The Client (students), which has the mobile phone, is responsible for presentation logic and the remaining part of application logic. The architecture is shown below.

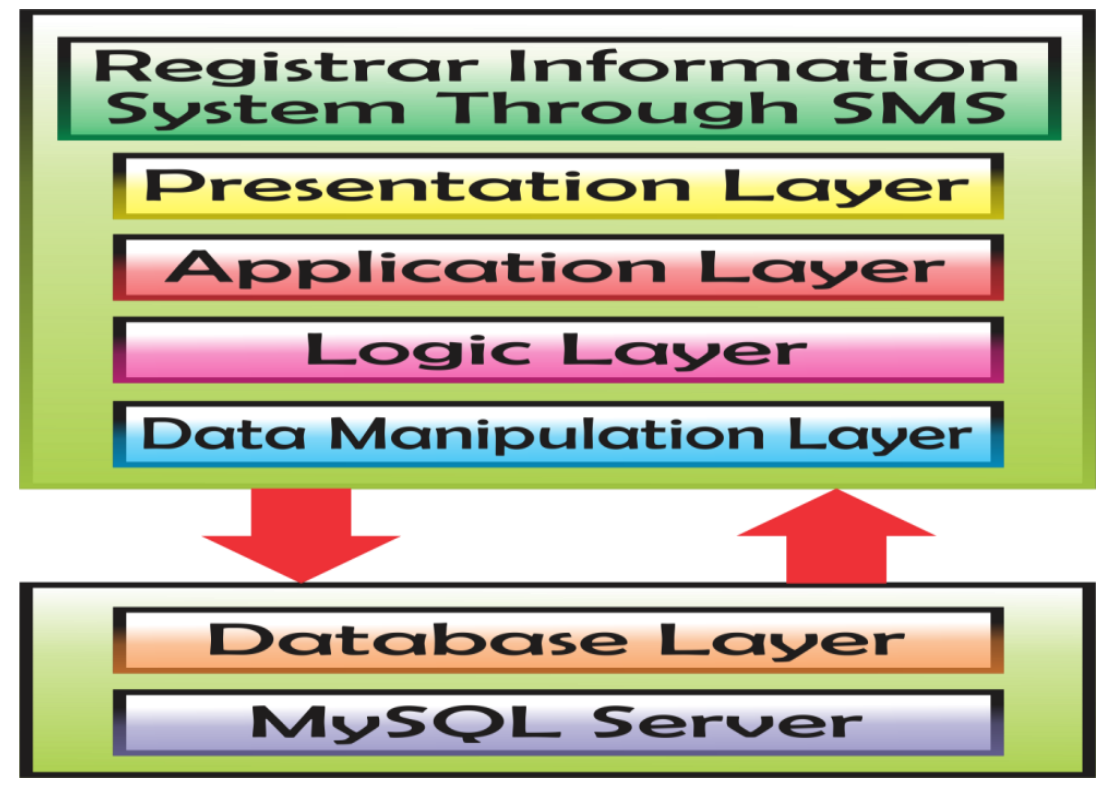

Figure 2: The Logical Architecture Design of the Proposed System

\subsection{Physical Network Topology}

Physical network topology is about the layout of computers in a network. How computers are wired and how computers and other devices are connected to each other determines the physical topology [8]. The developed system has an SMS support with the help of GSM Modem wherein it specialized type of modem which accepts a SIM card, and operates over a subscription to a mobile operator, just like a mobile phone.

When a GSM modem is connected to a computer, this allows the computer to use the GSM modem to communicate over the mobile network [9]. While these GSM modems are most frequently used to provide mobile internet connectivity, it is used for sending and receiving SMS and MMS messages for the developed system that allows the students to receive a notification about their academic records. The figure 3 shows the physical network topology of the developed system.

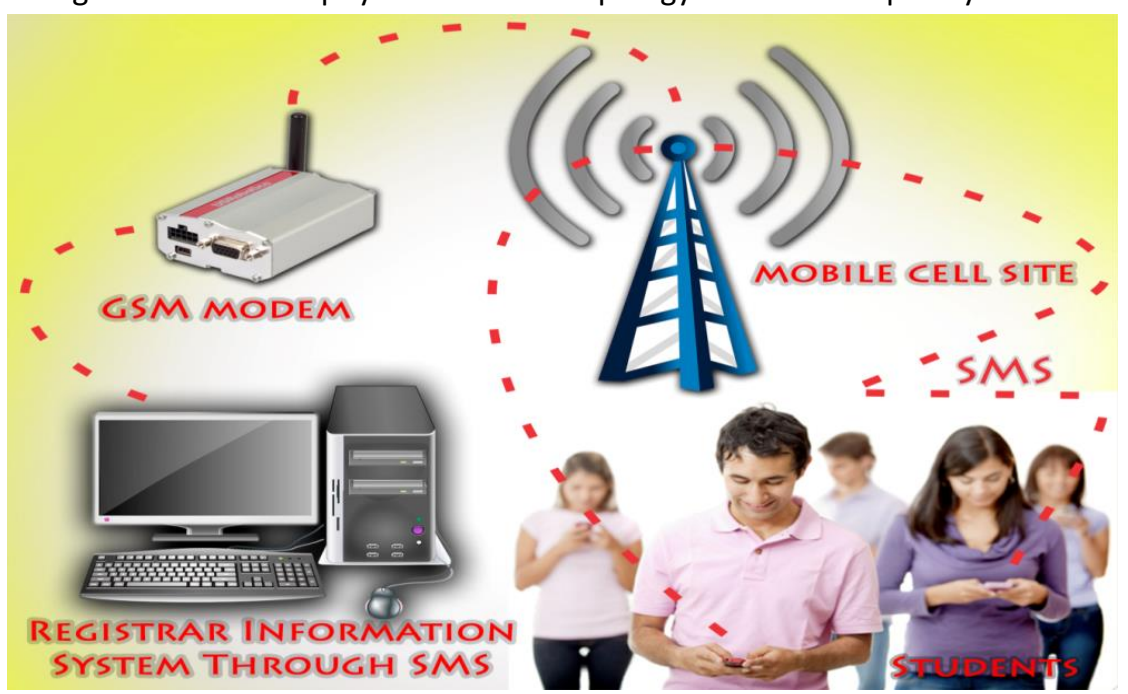

Figure 3: Physical Network topology of the proposed system.

\subsection{Proposed System Prototype}

\section{The Main Form}

The figure 2 shows the main form. This form is used to navigate the whole system. It includes the Data entry, Transaction, Setting, User. Also a menu for Enrolled, Request, Grade, User and Exit. 


\section{Registrar Information System through SMS}

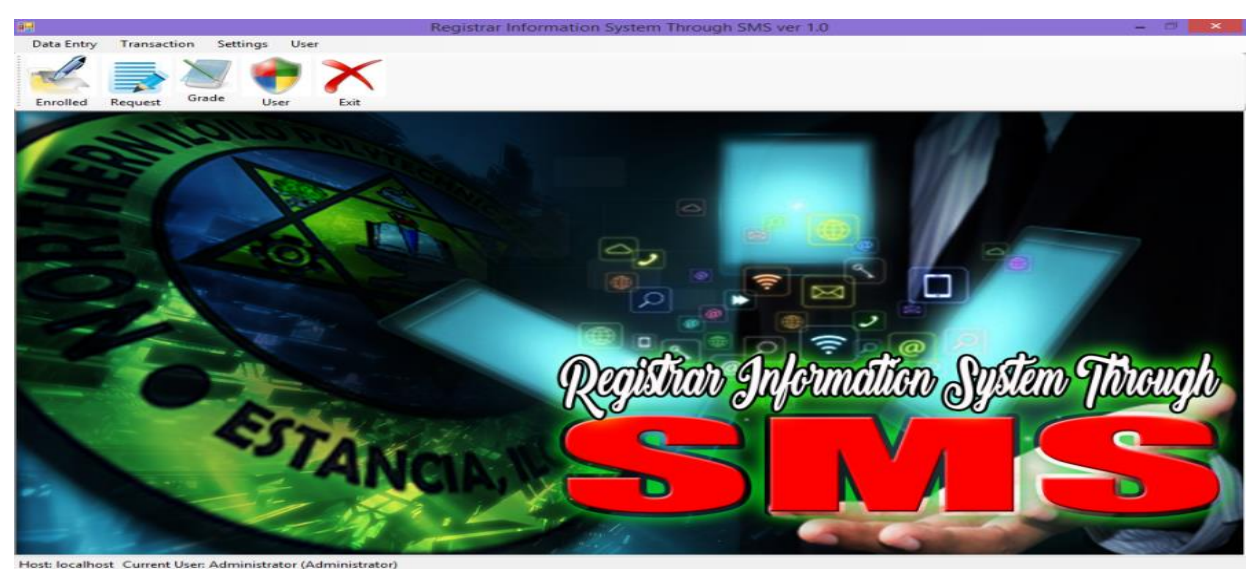

Figure 4. Main form

\section{The Data Entry}

This figure 5 shows the data entry. Under this data entry there's a module they are the course, subject, course subject, students, particulars SMS panel and exit. In figure 4, it shows the form of the course module wherein it displays the course information such as the course code and the course. The user can search into the search code box just encode course code intended for a different course.On the left side of the screen, there are the buttons for the new, edit and delete. The researcher can add the new course offered by the institution, edit and delete.

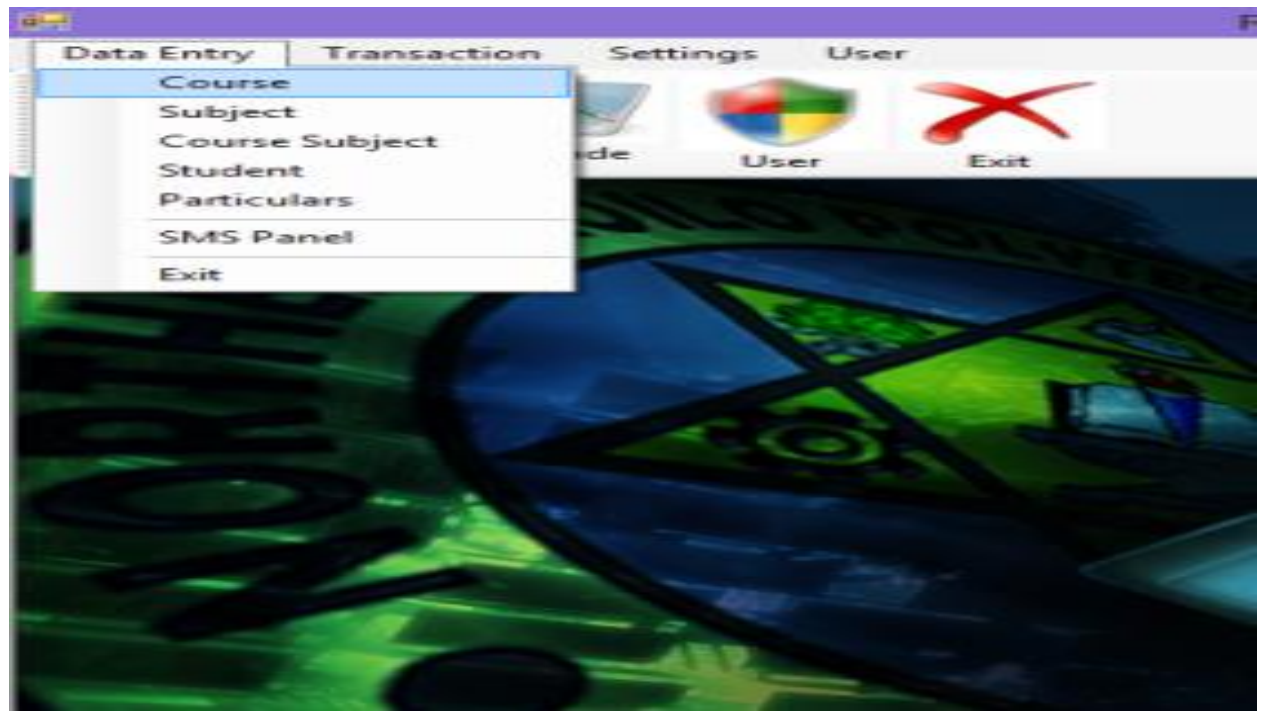

Figure 5. Data Entry

\section{RESULTS AND DISCUSSION}

\subsection{Functionality of the System Product}

The result showed of the respondents' feedbacks on the functionality of the system product in terms of Functional completeness, Functional correctness, and Functional appropriateness. In sending academic information of the students through SMS notification, the functional completeness $(M=4.39)$, functional correctness $(M=4.56)$, and functional appropriateness $(M=4.64)$ were described as "Very Good".

The findings implied that the functionality of the system product is very good in the day to day transactions. It showed that the users believed that the system has a manageable and easy to click menus for easy operation and management. Table 1 shows the results.

Table 1. Respondents' Feedbacks on the Functionality of the System Product.

\begin{tabular}{|l|l|l|}
\hline Implementation Indicators & Mean & Verbal Interpretation \\
\hline Functional completeness & 4.39 & Very Good \\
\hline Functional correctness & 4.56 & Very Good \\
\hline Functional appropriateness & 4.64 & Very Good \\
\hline
\end{tabular}




\section{Registrar Information System through SMS}

\subsection{Level of Usability}

The result showed that the level of usability of the Registrar Information System Through SMS was evaluated in terms of learnability, operability, and accessibility. The respondents' feedbacks for the usability in terms of learnability (M=4.69), operability ( $M=4.64)$, and accessibility ( $M=4.56)$ were all interpreted as "Very Good".

The findings implied that using the Registrar Information System Through SMS is greatly operable, learnable, and needed by the Registrar's office. The transaction involves by sending information such as diploma, if they are already officially enrolled, TOR (Transcript of Record), certificate, honorable dismissal and also can send the grades of the students per subject. The users believed that through the features of the system. The registrar can be able to access and perform their tasks as expected from them especially in sending the said information through SMS.

Table 2. The Level of Usability of the System Product.

\begin{tabular}{|l|l|l|}
\hline Implementation Indicators & Mean & Verbal Interpretation \\
\hline Learnability & 4.69 & Very Good \\
\hline Operability & 4.64 & Very Good \\
\hline Accessibility & 4.56 & Very Good \\
\hline
\end{tabular}

\subsection{Performance Evaluation of the System Product}

Performance is one of the essential quality attribute of software. Users of software usually regard performance as an important standard to decide whether the software is good to use. The evaluated performance of the system product showed the result in terms time efficiency $(M=4.52)$ and reliability $(M=4.58)$ were interpreted as Very Good.

The findings implied that on designing a system that is able to provide real-time information through SMS to students regarding of their academic records from the system product for the registrar of Northern lloilo Polytechnic State College. The performance of the system product reflects the time efficiency of the software that provides a proper use of resources that running fast.

Table 3. The Performance Evaluation of the System Product.

\begin{tabular}{|l|l|l|}
\hline Implementation Indicators & Mean & Verbal Interpretation \\
\hline time efficiency & 4.52 & Very Good \\
\hline Reliability & 4.58 & Very Good \\
\hline
\end{tabular}

\section{CONCLUSIONS}

Based on the interpretation that was discussed, the following conclusions were arrived:

The Registrar Information System Through SMS was functional that were able to deliver to students the complete data, correct information about their academic records and it is appropriate because it facilitate the accomplishment of specified tasks in the system product.

The Registrar Information System Through SMS gives the satisfaction to the respondents in a way that the system product is learnable because it is a user friendly, operable since it can be able to encode grades of the students and as well as accessible to the registrar office to send the academic information through SMS.

The performance of Registrar Information System Through SMS can be able to accomplished the amount of work and to provide real-time information through SMS to students regarding of their academic records.

\section{RECOMMENDATIONS}

From the findings and conclusions of the study, the following recommendations were strongly suggested:

Since automation and computerization is adapted in school, it maybe suggested that the Registrar Information System Through SMS be implemented and used by Northern Iloilo Polytechnic State College to help the registrar in managing and sending academic information to the students and other important tasks assigned.

The institution may conduct trainings to the intended users for the familiarization of the system especially during data entry of important inputs for the system to work. 


\section{Registrar Information System through SMS}

The school may continue to update the system which may help to maximize its potential and improve its functionalities, reliability and efficiency.

\section{REFERENCES}

1) https://www.mashable.com.ph/?gfe $r d=c r \& e i=D U i W S R M M T E X q y Q i L g P \# q=w h a t+i s+s m s$.

2) Olaleye, O., Olaniyan, A., Eboda, O., Awolere, A. (2013). SMS-Based Event Notification System. Retrieved from http: //REGISTRAR\%20INFO\%20SYSTEM\%20THROUGH\%20SMS/Related\%20Literature/7637-10053-1-PB.pdf. Journal of Information Engineering and Applications,pp 1-8.

3) http://www.campusexplorer.com/college-advice-tips/D4193496/What-Is-the-College-Registrar/ Aasen, R. (2011). Software Requirements Specification for SplitPay. Retrieved from https://www.cise.ufl.edu/class/cen3031sp13/SRS_Example_1_2011.pdf

4) Camad, J.M., Cabarrubias, W., Tobias, R.J, Rusiana, R., Baay, R., Bermudez, L.C. UC-Main Registrar's Office Student Document Management and Monitoring System. Retrieved from http://REGISTRAR\%2OINFO\%20SYSTEM\%20THROUGH\%20SMS/Related\%20Literature/IT-FullPaper-13.pdf on November 7, 2018.

5) Ali, F.A.B.H., Alqushaibi, A. A. M. (2013). Malaysia Yemen Student Information System with SMS Notification. Retrieved from https://pdfs.semanticscholar.org/85d0/f85025a0dec6ab3d47967f2b722c81db49a6.pdf,pp 5-8.

6) Sarmila. (2012). Phases of RAD. Retrieved from http://www.ftms.edu.my/images/Document/IMM006\%20\%20RAPID\%20APPLICATION\%20DEVELOPMENT/Chapter\%202nnote.pdf

7) https://www.techopedia.com/definition/467/two-tier-architecture

8) Ed, T. (2002) Theory and Problems of Computer Networking. USA: Schaum's Outline Series, McGRAW-HILL.

9) https://www.nowsms.com/faq/what-is-a-gsm-modem 